\title{
Editorial: Special Issue on Wireless Personal Multimedia Communications
}

\author{
António Rodrigues
}

Published online: 4 April 2009

(C) Springer Science+Business Media, LLC. 2009

The success of $3 \mathrm{G}$ networks implementation has brought great possibilities to the users in terms of new applications and services. However, necessary bandwidth and capacity resources are ever increasing. New techniques are thus needed to support future generation systems in the pursuit of higher access rates, better QoS or accessibility to networks. The economic health of modern societies and the perspectives of growth, particularly in Asia, are also very much dependent on the quick development of future wireless systems.

The series of international symposia on Wireless Personal Multimedia Communications (WPMC) are a splendid opportunity to globally exchange different views, bringing together operators, academia, service providers and manufacturers from all over the world.

This special issue was planned to include some of the best papers from a large number of research areas and groups, timely when WPMC 2007 was held at Jaipur, India from December 3-6, 2007.

It contains 14 papers which were accepted after peer review. These were chosen from a set of 22 papers selected among the excellent papers originally presented at WPMC 2007, including awarded papers. The papers have been revised and resubmitted to this special issue.

This issue covers a large number of topics including channel modelling, UWB, precoding for MISO systems, space-time coding in cooperative networks, software defined radio wireless sensor networks, cognitive radio, advanced spectrum and radio resource management, DVB-H, location based services, fixed-mobile network planning convergence, routing in ad-hoc networks and network security.

The guest editors would like to express their sincere thanks to all the authors who submitted papers and to the reviewers who provided revision reports for this special issue. Also,

A. Rodrigues $(\varangle)$

IT - Lisboa, Instituto de Telecomunicações, Av. Rovisco Pais, 1, Lisboa 1049-001, Portugal

e-mail: ar@1x.it.pt 
we would like to thank Cindy Zitter and Mark de Jongh, for their assistance with this special issue.

Guest Editors

Uday B. Desai

Neeli Rahmi Prasad

António Rodrigues

Vishwanath Sinha 